MAGNARTO प्राम

(4)

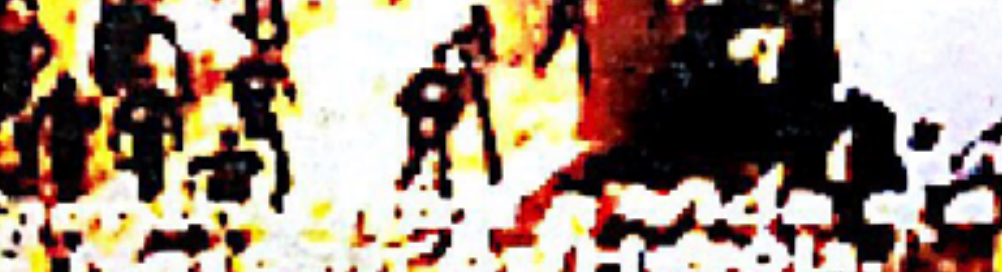

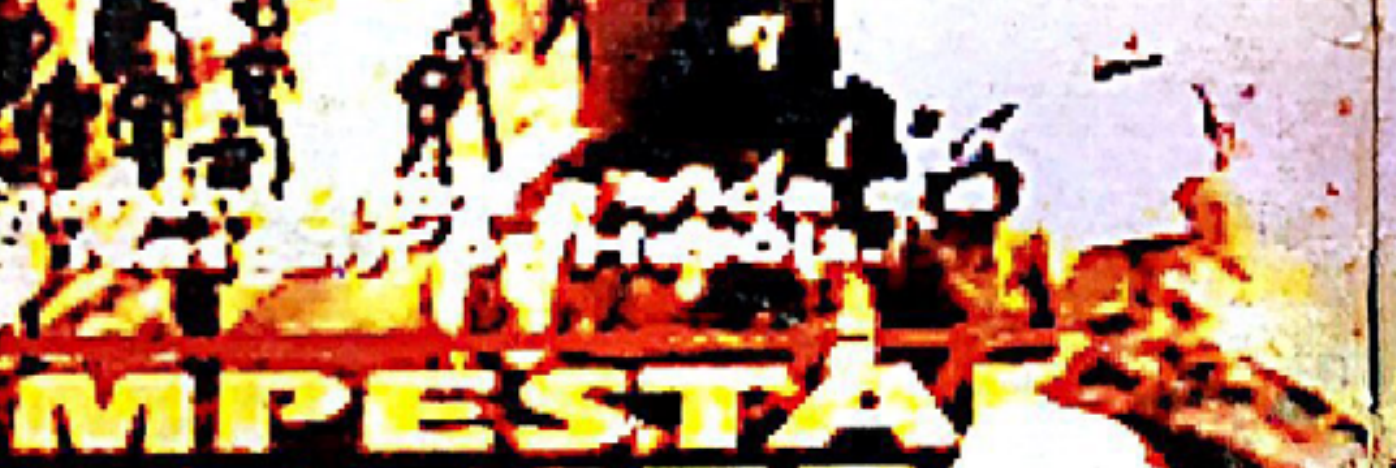

$2 D S T=15$

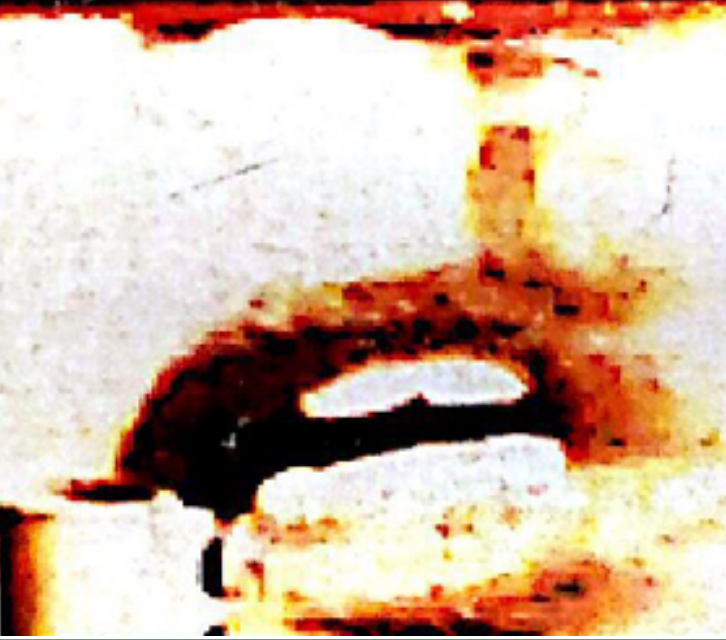

A estética do imaginário no cinema

Demian Garcia e André A. Medeiros P. 94

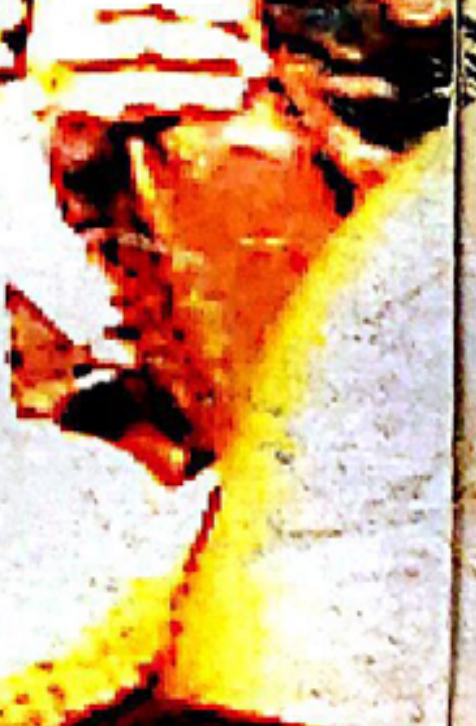

$+$

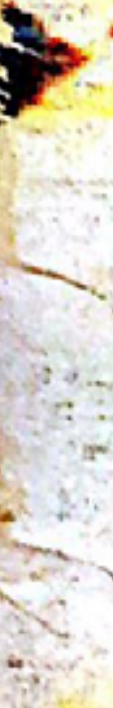

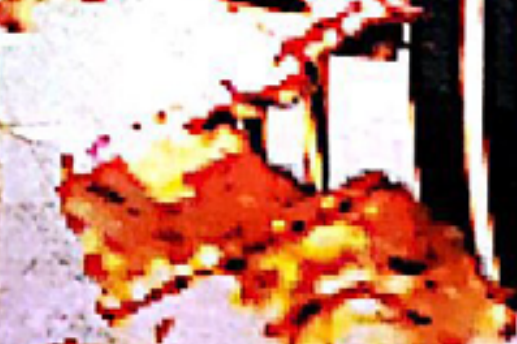

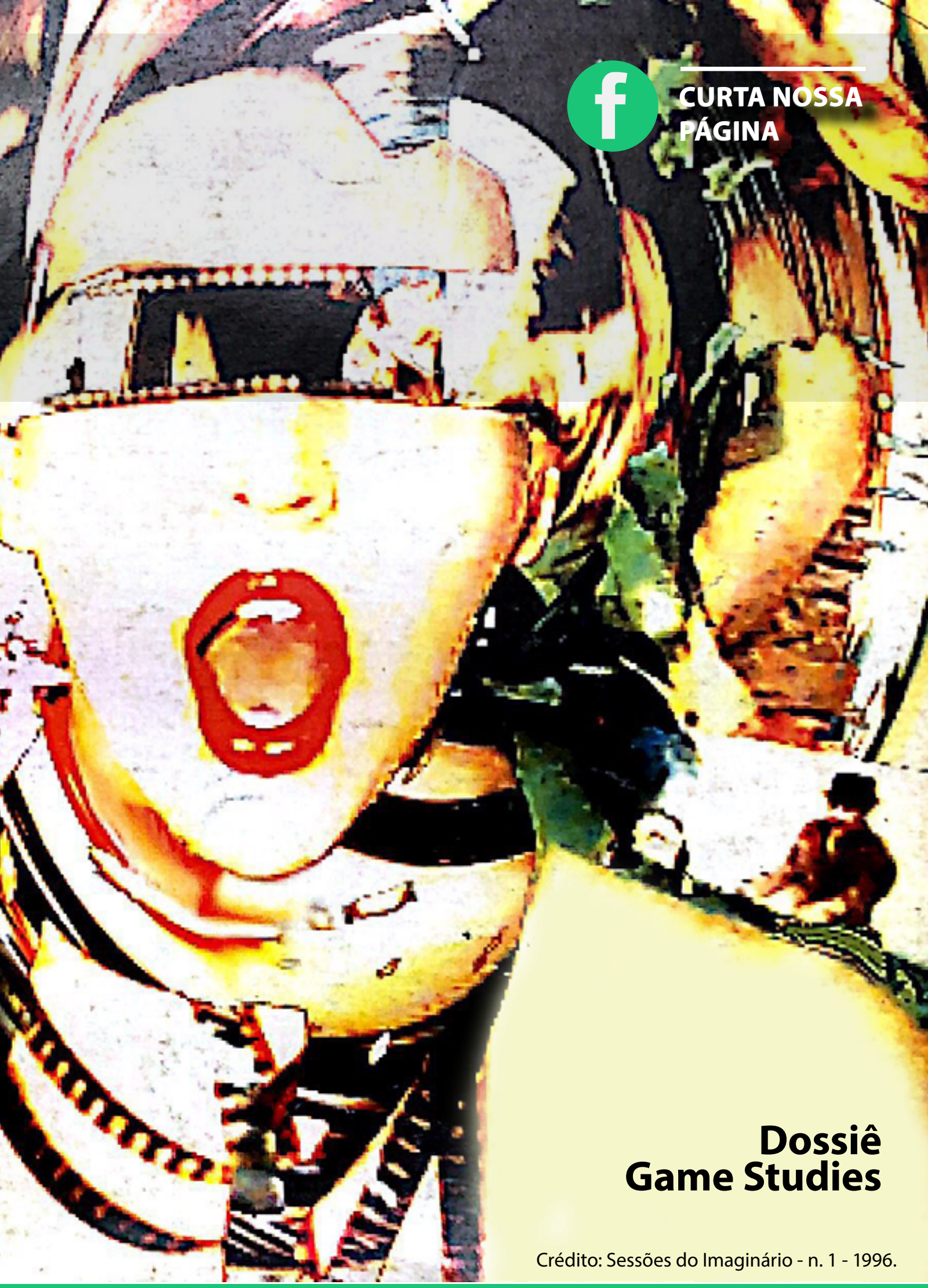

Materialidades fílmicas, magia e montagem

Ednei de Genaro

P. 112

Videogames, transgressão e criatividade no Brasil

Emmanoel Ferreira 


\section{A questão da autonomia do roteiro cinematográfico}

\section{On the autonomy of the screenplay}

\section{Alfredo Suppia' $\square$}

Natasha Romanzoti ${ }^{2}[\pi$

\section{Resumo}

A teoria e prática do roteiro tem lugar de inequívoca relevância no ensino superior de cinema e audiovisual. Não obstante, no âmbito da pesquisa e reflexão teórica acerca das artes cinemáticas, especialmente em nível da pós-graduação, o roteiro costuma ser deslocado em importância pelo produto final, o filme. É possível constatar uma variedade de pesquisas que equalizam em importância o roteiro ao filme, ou que privilegiam o roteiro como objeto principal de estudo. Mesmo assim, no caso dos estudos contemporâneos de cinema, no Brasil, tais pesquisas ainda subsistem marginalmente. $O$ objetivo deste artigo é investigar a autonomia do roteiro em estudos de cinema e audiovisual. Deve o roteiro ser tratado como um gênero literário? Pode o roteiro ser divorciado do filme?

\section{Palavras-chave}

Cinema; roteiro; teoria do cinema.

\section{Abstract}

The theory and practice of the script takes place of unequivocal relevance in the superior education of cinema and audiovisual. Nevertheless, in the scope of theoretical research and reflection on cinematic arts, especially at the postgraduate level, the script is usually displaced in importance by the final product, the film. It is possible to verify a variety of research that equalizes in importance the script to the film, or that privilege the script as the main object of study. Even so, in the case of contemporary film studies in Brazil, such research still subsists marginally. The objective of this article is to investigate the autonomy of the screenplay in film and audiovisual studies. Should the script be treated as a literary genre? Can the script be withdrawn from the movie?

\section{Keywords}

Film; screenplay; film theory.

199 PORTO ALEGRE | v. 22 | n. 38 | 2017 | p. 199-208 DOI: http://dx.doi.org /10.15448/1980-3710.2017.2.29616 Sessões do Imaginário 


\section{Introdução}

Em nossa disciplina "Oficina de Roteiro" I e II, no âmbito do curso de graduação em Comunicação Social - Midialogia da Universidade Estadual de Campinas (Unicamp), além de uma variedade de manuais, costumamos aplicar como bibliografia básica, com recomendação regular de leituras, os livros Prática do roteiro cinematográfico, de Jean-Claude Carrière e Pascal Bonitzer (1996), e A linguagem secreta do cinema, de Jean-Claude Carrière (2015). A nosso ver, Prática do roteiro cinematográfico se destaca como um "manual" diferenciado, um livro que vai além da repetição e pasteurização de fórmulas vulgares. O livro traz uma dimensão pedagógica e de testemunho ausente na maior parte dos manuais de roteiro. Carrière começa por dizer que

[...] [O] roteiro representa um estado transitório, uma forma passageira destinada a se metamorfosear e desaparecer, como a larva ao se transforma em borboleta. Quando o filme existe, da larva resta apenas uma pele seca, de agora em diante inútil, estritamente condenada à poeira. Se for publicado - o que ocorre às vezes -, não se tratará realmente de um roteiro, mas sim de uma narrativa recomposta depois do filme.

Objeto efêmero: o roteiro não é concebido para perdurar, mas para se apagar, para tornar-se outro. Objeto paradoxal: de todas as escritas, o roteiro é a que contará com o menor número de leitores, talvez uma centena, e cada um desses buscará nele o seu próprio alimento: o ator, um papel; o produtor um sucesso; o diretor de produção, um percurso inteiramente traçado para a fixação de um plano de trabalho (Bonitzer; Carrière, 1996, p. 11).
A ênfase na transitoriedade do roteiro parece sintoma de uma percepção e de um contexto econômico e cultural mais amplo, ao mesmo tempo em que pode ter influenciado razoavelmente a chave de abordagem de roteiros no campo dos estudos de cinema e audiovisual. Por exemplo, Carrière sugere uma hierarquia da imagem sobre o texto, no que diz respeito ao cinema, por conta da universalidade da primeira. Falando sobre a linguagem cinematográfica:

Ao contrário da escrita, em que as palavras estão sempre de acordo com um código que você deve saber ou ser capaz de decifrar (você aprende a ler e a escrever), a imagem em movimento estava ao alcance de todo mundo. Uma linguagem não só nova, como também universal: um antigo sonho (Carrière, 2015, p. 20)

Carrière crê tanto nessa superioridade da imagem que chega a apontar os potenciais perigos do que chama de "cinema de roteirista", no qual o conteúdo tem mais importância do que a forma ${ }^{3}$. Por outro lado, Carrière alerta que "[u]m roteiro já é o filme" (1996, p. 12),

Pois o roteiro significa a primeira parte de um filme. E quanto mais o próprio filme estiver presente no texto escrito, incrustado, preciso, entrelaçado, pronto para o voo como a borboleta, que já possui todos os órgãos e todas as cores sob a aparência de larva, mais a aliança secreta - e quase maternal de todo jeito parental - entre o escrito e o filme terá chances de se mostrar forte e viva (Bonitzer; Carrière, 1996, p. 12).
Ainda segundo Carrière, "[o] roteirista rapidamente deve aceitar - sem nenhuma pena, ao contrário - que não é um romancista, mas um cineasta" (1996, p. 13). A diferenciação decorre do fato de que o roteiro é uma forma passageira, ou seja, uma obra destinada a se tornar outra coisa. Em outra ocasião, Carrière acentua a severidade: "[u]ma vez que o filme esteja pronto, o roteiro não mais existe" (2015, p. 117). Será mesmo?

O objetivo deste artigo é justamente investigar a autonomia do roteiro. Deve o roteiro ser tratado como um gênero literário? Pode o roteiro ser divorciado do filme?

\section{O roteiro como transitório,}

\section{híbrido e programático}

Vilém Flusser é severo com o roteiro e os roteiristas. Em princípio, o pensamento de Flusser converge para o de Carrière, mas vai além: o filósofo localiza o roteiro como artefato híbrido ou limítrofe, a meio caminho não apenas entre a literatura e o cinema, mas também entre a escrita alfabética e a linguagem de máquina, a programação ou o algoritmo. Para Flusser,

Um roteiro é algo híbrido: uma metade ainda é um texto de um drama a ser encenado e, como tal, descendente de Sófocles; a outra metade já é programação de aparelho e, como tal, antepassado dos programas calculados automaticamente por inteligência artificial (Flusser, 2010, p. 202).

Logo de início Flusser antevê uma transformação cultural profunda: o analfabetismo do futuro não será aquele dos iletrados, mas dos incapazes de "escrever" programas de computador ${ }^{4}$. Antes de fechar o círculo 
de sua argumentação em torno dessa problemática, Flusser (2010) compara a leitura do roteiro à leitura da peça teatral. Para ele a leitura de Macbeth, de Shakespeare, por exemplo, pode ser feita antes, depois ou independentemente do espetáculo teatral. $\mathrm{O}$ mesmo não se aplicaria à leitura do roteiro. Uma pesquisa interessante, a qual talvez ainda reste por ser feita, seria comparar a história da leitura de peças de teatro com a história da leitura de roteiros. Seria possível medir a transitoriedade do roteiro em relação à "perenidade" da peça de teatro?

Para Flusser, o roteiro (e aqui ele se concentra no comentário sobre o roteiro radiofônico) não é independente do produto final. Se um roteiro não deságua em programa (radiofônico) ou filme, isso ocorre, segundo Flusser, por se tratar de um "mau" roteiro, inadequado à programação (2010, p. 204). Nesse sentido, o filósofo propõe que roteiros "[...] não são mais textos, eles são pretextos (Prätexte)", e explica que, "[n]o caso desses roteiros, trata-se de linhas de letras que devem ser transcodificadas em imagens. Neles, o alfabeto tornou-se um código auxiliar. Seu propósito é produzir imagens" (Flusser, 2010, p. 205). A metáfora de Carrière, aquela do roteiro como páginas amassadas na lata de lixo do set de filmagem, ecoa na filosofia de Flusser:

Um texto de letras degradado como subterfúgio para imagens não pode ser nada mais do que um fenômeno de transição. Escrevem-se roteiros porque, temporariamente, ainda encontram-se aparelhos aferidos pelo alfabeto em todos os lugares: máquinas de datilografar, processadores Word e o cérebro que armazena o alfabeto, por exemplo. Seria um desperdício deixar esses aparelhos sem uso (Flusser, 2010, p. 206).
Transitório emerge como um adjetivo intrínseco ao roteiro já em Carrière (1996; 2015), mas sobretudo em Flusser (2010). Pois o trecho citado acima deixa entrever uma dupla transitoriedade: não apenas aquela do texto escrito que deve resultar em imagens, mas também a do alfabeto fonético, ou da língua natural, como um código também transitório, esquemático, informativo. Pensemos, por exemplo, no roteiro de um filme de animação digital, 100\% elaborado em computador. O roteiro, neste caso, para se tornar um filme, resultará em um "roteiro" de segunda ordem, o da programação em linguagem de máquina, linguagem artificial. Pressentimos aqui uma dupla de/codificação: do roteiro alfabético para o roteiro computacional, e deste finalmente passa-se ao resultado final, o filme. Essa "dupla de/codificação" intuída ou pressentida aqui também pode ser ela mesma transitória, um fenômeno de passagem. Pois chegará o tempo, se é que já não chegou, em que inteligências artificiais serão capazes de roteirizar produtos audiovisuais, sem a necessidade do alfabeto fonético. Programas de computador capazes de oferecer a edição randômica de um filme, sem interferência direta de um editor humano, já fazem um pouco isso. E novamente Flusser se faz premonitório:

Muito em breve, não se terá mais de ver as imagens passarem em carruagens, e os roteiros abrirão espaço para prescrições imagéticas codificadas de maneira mais funcional. Por isso, os roteiros são um duplo engano: eles simulam ser textos, quando de fato são programas de imagens; e simulam que o alfabeto ainda tem uma função na cultura das imagens, quando de fato aproveitam apenas dos restos mortais do alfabeto no seu último suspiro, antes que a totalidade desapareça do campo de visão (Flusser, 2010, p. 206).
A partir daí, Flusser intensifica a aspereza de seu julgamento, conferindo um tom catastrófico e algo conservador ao conjunto de sua avaliação. O filósofo vaticina que

Os roteiros são o canto do cisne dos textos: tratase da despedida melancólica da literatura e com ela da história, no sentido preciso dessa palavra. 0 essencial nos textos é que eles dirijam-se aos leitores. Os roteiros não fazem mais isso. Aquilo que é essencial nos textos, seu núcleo duro, volatilizou-se com os roteiros. Eles são apenas nebulosos fantasmas de texto que flutuam em torno do túmulo da literatura por volta da meia-noite da cultura escrita, antes de o vento matinal da incipiente cultura digital purificar o ar (Flusser, 2010, p. 206).

Será mesmo? Flusser escreveu esse texto originalmente em 1987, sob forma de livro e dois floppy disks (os hoje desaparecidos disquetes flexíveis para PC). Atualmente, perguntamo-nos se o "vento matinal" da cultura digital continua tão "incipiente" assim, e se de fato os roteiros não se dirigem a leitores. Talvez o roteiro enquanto "arauto" da morte do texto nunca venha a se confirmar de fato, conquanto sobrevivam os leitores. Porque por mais transitório que seja o roteiro - e no caso falemos de roteiro cinematográfico -, ele sempre será lido. Talvez não por um público tão amplo, mas sempre por um público específico, aquele dos profissionais e artistas envolvidos na realização de um filme. Não há como negar que roteiros têm seu público leitor, independentemente de seu sucesso ou fracasso na transmutação de crisálida em borboleta - recorrendo a outra metáfora de Jean-Claude Carrière (2015). 
Senão vejamos: quantos roteiros são lidos diariamente por produtores de cinema e TV, júris de festivais ou editais públicos? E no contexto de cursos livres ou universitários, oficinas ou comunidades virtuais? Talvez mais ainda do que a frequência a cursos especializados, a escrita e leitura de roteiros seja uma prática fundamental na formação do roteirista. Nesse sentido, roteiros dirigem-se também a um tipo específico de leitor: o roteirista. Essa rotina pode ser depreendida do depoimento de Peter Mayersberg, que iniciou sua carreira na crítica de cinema, passou a funções técnicas ou de apoio em produções dirigidas por Joseph Losey e Roger Corman, e nesse ínterim passou a escrever dezenas de roteiros, nem sempre a pedido de alguém. Somente seu $39^{\circ}$ roteiro veio a ser filmado: $O$ Homem que Caiu na Terra (The Man Who Fell to Earth, Nicolas Roeg, 1976). A partir de então Meyersberg consolidou sua carreira de roteiristas. Os depoimentos de Mayersberg a propósito de sua colaboração com o diretor Nicolas Roeg sugerem eventuais pistas acerca de uma concepção de roteiro (e de roteirização) mais ampliada, ao mesmo tempo mais autônoma e mais orgânica em relação ao filme, para além de um simples "guia" verbal do produto audiovisual final. Mayersberg (1975) insinua uma continuidade do roteiro para além do início das filmagens, algo sugerido ou entrevisto a partir de seus relatos sobre o processo de adaptação, escrita e produção de $O$ Homem que Caiu na Terra. Talvez à diferença do relato de Jean-Claude Carrière, para quem o roteiro está destinado ao chão ou à lata de lixo dos sets de filmagem, o roteiro segundo Mayersberg ecoa nos mais diversos momentos da realização cinematográfica, chegando à mesa de montagem e para além do filme em si mesmo. Ainda segundo Mayersberg, "[o] verdadeiro roteiro de cinema, o qual não é um romance finamente disfarça- do, é frequentemente difícil de ser compreendido por produtores, companhias, distribuidores e mesmo atores" (1975, p. 231). O próprio Carrière, porta-voz primevo da evanescência do roteiro, admite que,

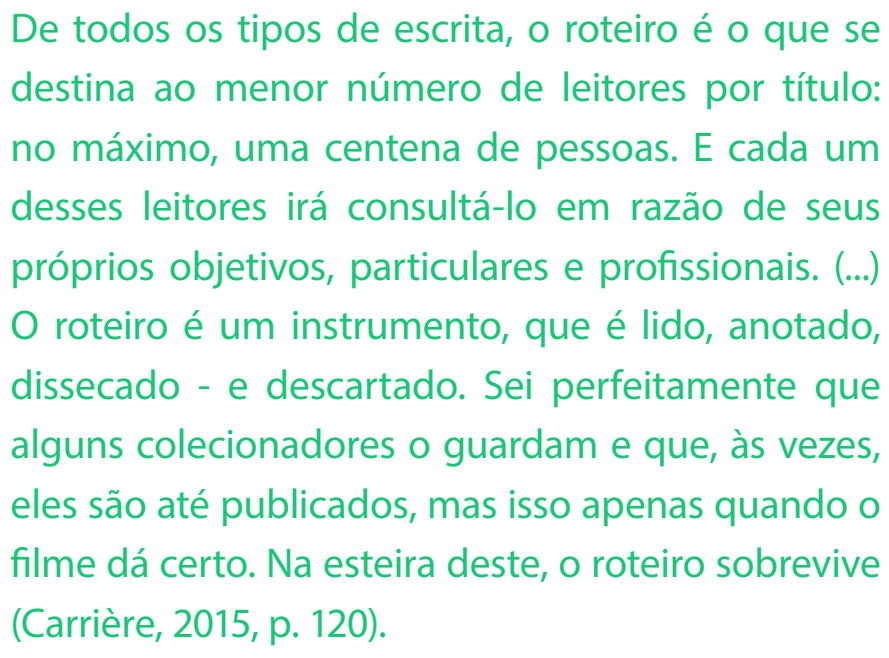

Por mais pessimista que seja o prognóstico acerca do público leitor de um roteiro, na ponta do lápis os números não nos parecem assim tão desalentadores. Teria a poesia um público leitor significativamente maior? Pensemos também em séries de livros, lançadas no mercado editorial, e que consistem na publicação dos roteiros originais de filmes - casos de roteiros originais publicados pela Warner Brothers ${ }^{6}$, ou de edições especiais da revista francesa L'Avant-Scène Cinéma.

Mas voltemos a Flusser. Intensificando sua crítica do roteiro (radiofônico, televisivo, cinematográfico), Flusser se refere a ele como "[...] uma fraude do pensamento discursivo, de uma traição ao espírito da escrita" (2010, p. 208). Segundo o filósofo, os roteiristas são aqueles que vendem sua alma ao demônio por renderem-se totalmente à cultura das imagens - que é, do ponto de vista da cultura escrita, o próprio demônio. Flusser é intransigente: não apenas do naufrágio da escrita e da literatura tiram vantagem os roteiristas, mas também os roteiros seriam responsáveis pela "traição" da história, uma traição que não sentimos, "[...] dia e noite, porque já perdemos a consciência histórica em frente à TV e no cinema" (2010, p. 210).

Apesar dos termos intensos, apocalípticos até, a visão eventualmente negativa de Flusser não é de todo estéril, e guarda uma curiosa ambiguidade. Porque ao mesmo tempo em que se refere tão duramente ao roteiro e aos roteiristas, reconhece que "[...] a história, que há três mil anos brotou das imagens, corre, por meio dos vasos capilares dos roteiros, de volta para as imagens" (Flusser, 2010, p. 209). Antes mesmo, Flusser assinala que "[o]s roteiros escrevem em direção aos códigos digitais" (2010, p. 208), no que não poderíamos deixar de concordar. Sob uma ótica flusseriana, roteiros antecedem, em seu caráter programático (eles programam aparelhos ou dispositivos, a TV e o cinema, por exemplo), a linguagem de programação que hoje quase tudo regula ou rege, quando "o software toma o comando" - a mesma linha de pensamento de Manovich (2013), para quem os softwares são o fenômeno cultural mais relevante de nosso tempo, roteiros da vida contemporânea em todas as suas facetas.

Se discordamos de Flusser no que se refere a um eventual caráter deletério do roteiro enquanto instrumento de "traição" da cultura escrita, por outro lado valorizamos a conexão que o filósofo promove entre a cultura do roteiro e a cultura digital. Roteiros são, de fato, programas. Talvez programas pré-informáticos, pré-digitais, pré-algorítmicos, mas mesmo assim programas, (con)textos que ordenam o funcionamento de aparelhos e a feitura de artefatos - os filmes ou os vídeos, no caso dos roteiros audiovisuais. E programas de computador, ou algoritmos, são igualmente roteiros, 
porém destituídos das línguas naturais como código principal. No que julgamos conveniente revisitar a ideia de "notação", por Raymond Williams (2005).

Segundo Williams, existe uma crise na teoria cultural entre a visão da obra de arte como objeto, e uma visão alternativa da obra de arte como prática:

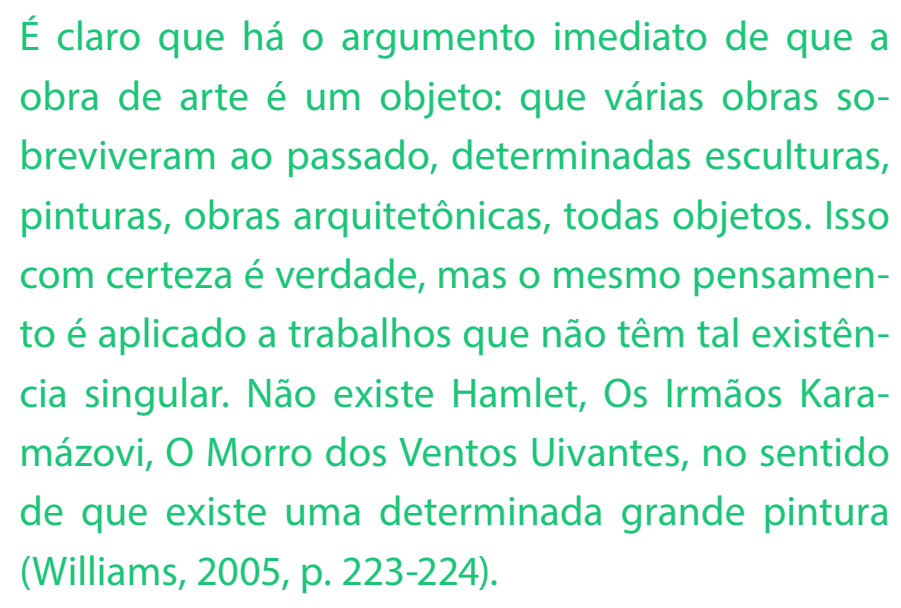

Para o autor, algumas formas de arte dispõem de uma variedade de registro à qual ele dá o nome de "notação", e cujo exemplo mais claro ou imediato seria o da música. Temos a música como obra em si, audível, mas também temos a partitura musical, sua manifestação sob forma de "notação". Nesse sentido, a peça de teatro poderia ser também compreendida como a "notação" do espetáculo teatral e, por extensão, o roteiro cinematográfico poderia também ser compreendido como a "notação" do filme. Williams e Flusser parecem convergir nesse ponto, embora por vias e nomenclaturas diversas:

Não há a Quinta Sinfonia, não há trabalho em toda a área da música, dança e atuação, que seja um objeto comparável àquelas obras das artes visuais que sobreviveram. Ainda assim, o hábito de tra- tar todas as obras desse tipo como objeto persistiu porque é uma pressuposição prática e teórica fundamental. Mas na literatura (principalmente no drama), na música e numa área muito ampla das artes cênicas, o que nós vemos permanentemente não são objetos e sim notações. Essas notações têm então de ser interpretadas de modo ativo, de acordo com convenções específicas. [...] Isso faz com que as notações, em artes como o drama, a literatura e a música, sejam apenas um exemplo específico de uma verdade muito mais abrangente. O que isso demonstra é que devemos, na prática da análise, romper com o procedimento habitual de isolar o objeto e então descobrir seus componentes. Pelo contrário, temos que descobrir a natureza de uma prática e então suas condições (Williams, 2005, p. 223-224)

Convém observar, porém, que Williams enxerga a "notação" de uma forma talvez mais ampla e menos elitista com que Flusser enxerga o "programa". Pois Williams concebe notações também na literatura e no teatro, enquanto Flusser contrapõe o roteiro cinematográfico a uma suposta perenidade ou autonomia da literatura e da dramaturgia.

De todos os autores aqui invocados, talvez David Bordwell seja o mais tolerante e inclusivo no que diz respeito a uma eventual autonomia do roteiro. No texto "Roteirografia", originalmente publicado em Obervations on Film Art, em 18/9/2011, Bordwell (2014) compila impressões em torno de sua participação na Quarta Conferência Anual sobre Pesquisa de Roteiros, promovida em Bruxelas, Bélgica, pela Screenwriting Resource Network, associação internacional de pesquisa sobre roteiros de cinema.
Bordwell inicia seu percurso argumentativo retomando Jean-Claude Carrière, para quem "[o] filme resiste ou perece em função do que vemos na tela" $(2014$, p. 3). Ele tende a concordar inicialmente com Carrière, sugerindo que, "[...] na melhor das hipóteses, o roteiro é um conjunto de sugestões para uma filmagem, e não uma versão em rascunho do filme" (Bordwell, 2014, p. 4). Antes do que ele mesmo pontua:

Alguém poderia lembrar que é comum analisarmos os estudos de um pintor, os rascunhos de um romancista ou as primeiras partituras de um compositor. Nessas artes, não obstante, o material preliminar também se encontra no mesmo meio que seu resultado final. Um roteiro, todavia, não pode ser contado como uma versão de um filme porque a prosa não consegue especificar de forma adequada a textura audiovisual do filme (Bordwell, 2014, p. 4).

Em seguida, Bordwell começa a apresentar suas impressões acerca dos trabalhos apresentados na Quarta Conferência Anual sobre Pesquisa de Roteiros em Bruxelas, demonstrando uma miríade de possibilidades epistemológicas e vetores de interesse em torno do roteiro como documento histórico, como documento parafílmico, como indício do estilo, como marca de um modo de produção, como gênero e mesmo processo criativo.

Todas essas investigações podem levar a reflexões mais amplas em relação ao processo criativo no cinema. Para alguns realizadores, um roteiro é uma tarefa profissional, levada a cabo com plena 
consciência de que haverá problemas ou restrições que precisarão ser enfrentados. Para outros, como Bergman ou Varda, trata-se evidentemente de algo profundamente pessoal, ou mesmo autobiográfico (Bordwell, 2014, p. 11).

Ao que se sucede a pergunta: "Como encarar o roteiro? Um rascunho? Uma receita? Um esboço?". E é então que Bordwell consolida uma revisão da transitoriedade do roteiro, seu caráter supostamente descartável ou de meio-termo:

Todos esses rótulos sugerem algo anterior ao objeto real - o filme - e descartável. Mas por que não pensar no roteiro como algo que se sustenta por si só? Afinal, há filmes sem roteiro, mas também há roteiros - alguns escritos por respeitados autores que nunca se converteram em filmes. Entre outros, o roteiro de Harold Pinter para Em Busca do Tempo Perdido, de Proust, é lido em si mesmo (Bordwell, 2014, p. 11-12, grifos no original).

$E$, se um roteiro nunca filmado pode se sustentar por si só, Bordwell se pergunta o que impede roteiros filmados de serem encarados da mesma forma:

Mais ainda, por que falar de um roteiro único, quando sabemos que a maioria dos filmes comerciais recebe vários tratamentos escritos? Não se poderia considerar cada um como um texto literário independente? Aqui, encontramo-nos bem longe da ideia de Carrièrre de que o roteiro encontra no filme sua finalidade, e que, como texto, deveria ser descartado (Bordwell, 2014, p. 11-12).
Embora revise a transitoriedade e descartabilidade do roteiro preconizadas por Carrière, Bordwell ressalva que, "[n]ão obstante, nem todo roteiro é um texto literário" (2014, p. 12). Ele cita como exemplo os cadernos de notas, colagens e assemblages ${ }^{7}$ de diversas mídias feitos por Agnès Varda no processo criativo de seus filmes. E aqui gostaríamos de introduzir uma reflexão mais detida.

A nosso ver, um roteiro não é um gênero literário. E não porque não se dirige a leitores, conforme sugere Flusser, mas por outro motivo. Um roteiro não é um gênero literário porque, a rigor, sua forma não é objeto de estilística, não é o que verdadeiramente distingue sua autoria, a marca do artista. A função precípua do roteiro é tornar-se um filme, ou programa para a TV (no caso do roteiro audiovisual). Por mais que tal função possa ser relativizada, secundarizada ou mesmo ignorada, ela continua sendo a função precisa de qualquer texto que reivindique o nome de "roteiro". Nesse sentido, um roteiro não se distingue por seu "estilo", mas por sua viabilidade, pela adequação de seu conteúdo a um determinado propósito, pelo interesse na história que ele veicula, prevendo-se uma tradução intersemiótica subsequente (do texto escrito para o produto audiovisual) com vistas ao preenchimento de uma "grade de programação".

Enquanto no gênero literário a forma da prosa é lugar do estilo - um romance de Machado de Assis difere de um de Lima Barreto também pela forma da prosa; um conto de Henry James difere de um conto de Edgar Allan Poe também por sua forma, assim como a prosa de José Saramago diverge da de Georges Perec, ou de Oswald de Andrade, e assim por diante -, um roteiro, por sua vez, via de regra não será rodado pela inovação de seu estilo literário, mas pelo interesse de seu conte- údo. Donde roteiristas mais ou menos sucedidos não o são pela singularidade de sua prosa ou estilo, mas pela singularidade ou banalidade da história que contam. Roteiros podem ser radicalmente inovadores em termos de temas, de trama ou de tessitura narrativa. Mas afora o fato de serem redigidos de forma clara, no padrão "americano" (Master Scenes) ou "europeu" (o roteiro de rádio e TV, em duas colunas) ${ }^{8}$, a rigor ninguém julga com muita atenção a forma da prosa empregada no roteiro. Mesmo porque roteiros seguem formatos um tanto quanto "burocráticos" por um motivo bem específico: são peças funcionais, de suposta leitura rápida e objetiva (embora também detida e repetida), que devem ser facilmente compreendidas por todos os seus leitores potenciais (produtores, diretores, diretores de fotografia, cenógrafos, atores, etc.).

Bons escritores podem ser bons roteiristas, mas não necessariamente. Não é preciso escrever como James Joyce para se criar um bom roteiro. Talvez, na contramão do gênero literário, o roteiro seja lugar do exercício de uma certa modéstia, de um certo "rebaixamento" estilístico que, não obstante, faz parte de sua função e não implica demérito da obra, tanto quanto tomemos o roteiro também como obra artística. Roteiros seguem padrões por conta de como os filmes são realizados. Um roteiro singularíssimo em termos de forma ou estilo, compreensível apenas por seu autor, só faz sentido se for objeto de um projeto personalíssimo, no qual o diretor produz, dirige, atua, monta, lança e assiste a seu filme.

Roteiros totalmente "abertos", totalmente liberados de qualquer formato ou padrão e plenos de subjetividade, também perdem sua função precípua. Afinal, para que um roteiro se a proposta é liberar totalmente o processo, produzir o que vier à cabeça de cada um? Nesses 
casos, parece-nos mais apropriado praticar o "não-roteiro". Isso não é novo, nem pouco usual. Por exemplo, cineastas que trabalham nos limites do cinema direto com a ficção, que valorizam o improviso ou o calor da hora, a "circunstância da tomada" (Ramos, 2012) e a resposta profilmica, mais do que "uma história a ser contada", praticam de variadas formas aquilo que chamamos aqui de "não-roteiro": filmes que se materializam na produção, e mesmo na pós-produção. Esse parece ser o caso de cineastas como Adirley Queirós, diretor de Branco sai, preto fica (2014) e Era uma vez Brasília (2017) (ver Suppia, 2017; Reis, Mena e Imanishi, 2013).

$\mathrm{Na}$ existência de um roteiro, no entanto, ele pode se dirigir a leitores. Para Flusser (2010), o fato justamente de o roteiro possuir uma função precípua é o que faz dele um texto que não pode ser lido de forma independente, que nos obriga a recorrer a um contexto maior. Retornando à comparação que Flusser faz da leitura de uma peça de teatro com a de um roteiro:

Lê-se o texto [da peça teatral] antes para se fazer uma ideia do drama. Lê-se o texto [da peça teatral] depois para se verificar o quanto da obra escrita se perdeu na dramatização e o quanto se acrescentou. Lê-se o texto [da peça teatral] independentemente para des-dramatizar a obra. Nos raros casos em que se lê um roteiro para o rádio, se está sempre embaraçosamente ciente de que o texto foi descontextu alizado - do contexto do programa, em específico e do contexto de toda a programação do rádio: o texto não é independente. [...]. A comparação do roteiro com um texto dramático indica uma mudança radical em nossa disposição. Nós não vivemos mais dramaticamente, nós vivemos muito mais programaticamente (Flusser, 2010, p. 149).

De fato, é difícil ler qualquer roteiro (de rádio ou audiovisual) somente como um texto dramático. É realmente necessário trabalho mental e disposição para separar a narrativa das marcas de produção que se encontram dispostas no texto, ainda que sutilmente. Mas isso não é tarefa impossível. Roteiros também podem se destacar por suas características dramatúrgicas. Embora Flusser os considere apenas "pré-textos" (2010, p. 150), eles podem ser na verdade tomados como texto e pretexto a um só tempo.

Prova disso é que há quem ame ler roteiros, tanto quanto há quem ame ler peças teatrais, e pelos mesmos motivos listados por Flusser (2010): para se fazer uma ideia do drama antes de se assistir ao filme; para verificar o quanto da obra escrita se perdeu ou se manteve na transposição para a mídia audiovisual; e inclusive de forma totalmente autônoma, visto que roteiros originais nunca filmados muitas vezes resistem ao tempo, sendo lidos e estudados, o que pressupõe a existência de um público para essas obras, ainda que restrito.

O fato de não ter sido filmado não invalida um roteiro, na verdade é razoável supor que, a cada centena de roteiros escritos, senão mais que isso, apenas meia dúzia venha a ser filmado. Embora de difícil mensuração, essa proporção poderia fornecer dados interessantes. $E$ o campo de investigação que concerne aos projetos de filmes ou roteiros jamais filmados parece crescer constantemente em importância. Pensemos na adaptação de O Capital, por S. M. Eisenstein, ou o Napoleão de Stanley Kubrick, ou em livros como o de David Hughes (2008), The greatest sci-fi movies never made, o qual comenta projetos como a adaptação de O Fim da Infância (Childhood's End), de Arthur C. Clarke, também jamais transcrito para a tela grande.

$E$, além de haver quem ame ler roteiros, há ainda quem ame escrever roteiros. Se alguém escreve roteiros por puro prazer, independentemente de qualquer ambição de vê-los filmados, talvez antes de ser roteirista, esse artista seja essencialmente apenas um escritor tout court - que recorre ao formato ou à técnica do roteiro para exprimir sua prosa. Nesse caso, o roteiro pode ser um formato, antes do que propriamente um gênero, apropriado pelo escritor em seu processo criativo e como opção estética. Talvez seja produtivo saber diferenciar os dois casos: aquele do roteirista, que escreve roteiros para o cinema, para a televisão, para os videogames ou ainda outra mídia, e o escritor que recorre ao formato do roteiro para se expressar. Para este, a indústria do entretenimento tem importância menor ou subsidiária.

\section{Considerações finais}

Talvez uma visão mais global do roteiro, sua função, valor e autonomia, possa lucrar com subsídios do pensamento de todos os autores visitados por este artigo. No que finalmente tentamos conciliar algumas das teses supracitadas. É possível aceitar a transitoriedade do roteiro e, ao mesmo tempo, reconhecer sua autonomia, ou mesmo seu status de arte autônoma? Acreditamos que sim.

Em sua função precípua, o roteiro é um texto de transição, um "programa" que determina/estabelece/ sugere/delineia um processo criativo dependente de um esforço de tradução intersemiótica. Mesmo que não venha a cumprir sua função, permanece sendo um roteiro. E caso o roteiro "atravesse essa ponte", vindo a ser filmado, continua sendo uma matriz importante, um documento eventualmente valioso no campo dos estudos de cinema e audiovisual, pesquisa histórica e/ou investigação artística. Talvez Carrière tenha sido muito intransigente com o roteiro, destinando-o ao chão do 
set ou à lata de lixo, e Flusser também tenha sido muito rigoroso em sua menção ao roteiro como uma peça indicativa de uma "fraude" ou "traição". Bordwell revisa o juízo de Carrière (2015) e salienta a autonomia e sobrevivência do roteiro a partir de seu testemunho de pesquisas contemporâneas, todas elas elegendo o roteiro como objeto de estudo privilegiado:

Aqueles interessados no cinema como arte podem aprender muito com os estudos de roteiros e sua escrita orientados por problemas específicos de pesquisa. Para os que se interessam pela história do cinema, as análises ajudam a mostrar como a organização da produção e as escolhas individuais de roteiristas e diretores moldam o produto final. Para os interessados em questões mais teóricas, reflexões sobre a natureza e o "modo de ser" do roteiro inevitavelmente levam à ontologia do cinema em si.

Além disso, para conhecer os filmes de forma ainda mais íntima, perceber as escolhas criativas feitas pelos cineastas ajuda a iluminar aspectos do filme que, de outra forma, não nos daríamos conta (Bordwell, 2014, p. 17).

De fato, o roteiro faz parte de uma cadeia de eventos ou processos, mas, dependendo do contexto, pode sobreviver a essa cadeia, ser resgatado, revisitado e até mesmo imortalizado. Senão vejamos: a indústria de remakes ${ }^{9}$, por vezes muito lucrativa, tem por pivô o filme ou o roteiro? Arriscamos dizer que toda a indústria de remakes cinematográficos (e mesmo as franquias) se baseia na sobrevivência de roteiros, mesmo que na esteira, é claro, do sucesso comercial e artístico dos filmes.
E, na contramão dos remakes, a sobrevivência e resgate de roteiros originais pode ser responsável até pela renovação da indústria cinematográfica. É o caso, por exemplo, de uma publicação chamada The Black List ${ }^{10}$ criada em 2005 pelo executivo de cinema americano Franklin Leonard, e que reúne os melhores roteiros não realizados pela indústria americana a cada ano. Leonard iniciou o projeto por estar insatisfeito com a falta de diversidade dos enredos escolhidos para serem produzidos pelos grandes estúdios americanos, questionando anonimamente seus colegas executivos sobre os melhores roteiros que eles leram, mas não selecionaram, classificando os resultados pelo número de menções. A lista anual se tornou um sucesso e mais de 300 dos roteiros citados acabaram sendo posteriormente produzidos. Dez dos últimos vinte vencedores da categoria de Melhor Roteiro das premiações da Academia de Artes e Ciências Cinematográficas (Oscar) uma vez já figuraram na The Black List.

Em entrevista ao jornal americano The Atlantic, Leonard afirmou que o The Black List faz uma pergunta diferente da que o mercado faz: "Estamos perguntando quais roteiros as pessoas adoram. $O$ mercado exige que elas respondam: 'Qual roteiro você acha que resultará em um filme rentável?'" (Wagner, 2017, tradução nossa)" ${ }^{11}$. O sucesso dos "azarões" listados é evidência de que a indústria ainda reconhece grandes histórias, mesmo que nem sempre as transforme em filmes, e de que os roteiros podem ser lidos com um certo prazer dramatúrgico em mente, pois contêm narrativas interessantes que não foram selecionadas justamente por terem sido consideradas, inicialmente, ruins do ponto de vista de sua função precípua - a de se tornarem produtos audiovisuais lucrativos.

De uma forma geral, é difícil negar um certo grau de autonomia do roteiro se considerarmos que ele pode continuar a ser relevante depois ou independentemente de ter cumprido sua função. Conforme abordamos aqui, roteiros podem existir sem dar origem a qualquer filme e ainda assim terem um público leitor, bem como podem ser estudados e consumidos à parte dos filmes aos quais estariam ligados. Ainda que, via de regra, o roteiro seja vinculado a uma função, onipresente em seu texto sob forma de "programação", um certo "grau zero" da independência do roteiro deve ser devidamente reconhecido. Afinal, como já disse Carrière, e não nos custa repetir aqui, "[u]m roteiro já é o filme" (Bonitzer; Carrière, 1996, p. 12). Mental e evanescente, cifrado numa língua escrita, mas ainda assim um filme.

\section{Referências}

BORDWELL, David. Roteirografia. Tradução e adaptação: Pedro Novaes. Janela, 26 out. 2014. Disponível em <http://janela.art.br/index.php/traducoes/roteirografia/>. Acesso em: 1 nov. 2017.

CARRIÈRE, Jean-Claude. A linguagem secreta do cinema. Rio de Janeiro: Nova Fronteira, 2015.

; BONITZER, Pascal. Prática do roteiro cinematográfico. São Paulo: JSN, 1996.

FLUSSER, Vilém. Die schrift. Göttingen: Immatrix Publications, 1987.

A escrita: há futuro para a escrita? São Paulo: Annablume, 2010.

HUGHES, David. The greatest sci-fi movies never 
made. London: Titan Books, 2008.

LEONARD, Franklin. The black list. Disponível em: <https://blcklst.com/>. Acesso em: 19 mai. 2018.

MANOVICH, Lev. Software takes command. Londres: Bloomsbury Academic; INT edition, 2013.

MAYERSBERG, Paul. The story so far... The man who fell to Earth. Sight and Sound, 1975, p. 225-231.

RAMOS, Fernão. A imagem-câmera. Campinas: Papirus, 2012.

REIS, Claudio; MENA; Mauricio Campos; IMANISHI, Raquel (2013), Entrevista com Adirley Queirós. Negativo, Brasília: Cineclube Beijoca/Universidade de Brasília, v. 1 n. 1, jul/set, p. 16-69.

SUPPIA, Alfredo. Acesso negado: circuit bending, borderlands science fiction e lo-fi sci-fi em Branco Sai, Preto Fica. Revista Famecos, Porto Alegre, v. 24, n. 1, janeiro, fevereiro, março e abril de 2017, p. 1-21. Disponível em: <http://revistaseletronicas.pucrs.br/ojs/ index.php/revistafamecos/article/view/24331/15017)>. Acesso em: 2 nov. 2017.

TES. Coding the future: is computer programming a 21st century literacy? Londres, 2 jul. 2013. Disponível em: <https://www.tes.com/articles/coding-future-computer-programming-a-21st-century-literacy $>$. Acesso em: 7 jan. 2018.

TRUFFAUT, François. O prazer dos olhos - escritos sobre cinema. Rio de Janeiro: JZE, 2005.
WAGNER, Alex. The Hollywood list everyone wants to be on. The Atlantic, Boston, mar. 2017. Disponível em: <https://www.theatlantic.com/magazine/ archive/2017/03/how-franklin-leonard-created-the -hollywood-list-everyone-wants-to-be-on/513830/>. Acesso em: 5 dez. 2017

WILLIAMS, Raymond. Base e superestrutura na teoria cultural marxista. Tradução de Bianca Ribeiro Manfrini com revisão de Maria Elisa Cevasco. Revista USP, São Paulo, n. 65, p. 210-224, mar/maio 2005, p. 211-224. Disponível em: <https://www.revistas.usp.br/revusp/article/viewFile/13448/15266>. Acesso em: 2 nov. 2017.

YAMASHITA, Iris. Letters from Iwo Jima. Burbank: Malpaso Productions and Warner Brothers, 2005.

\section{Referências Audiovisuais}

DEELEY, Michael. SPIKINGS, Barry. ROEG, Nicolas. [35 $\mathrm{mm}$ ]. O homem que caiu na Terra. Produção de Michael Deeley e Barry Spikings. Direção de Nicolas Roeg. Reino Unido, British Lion Film Corporation, Cinema 5 , 1976. $139 \mathrm{~min}$. Cor. Som.

EASTWOOD, Clint. SPIELBERG, Steven. LORENZ, Robert. [Digital]. Cartas de Iwo Jima. Produção de Clint Eastwood, Steven Spielberg e Robert Lorenz. Direção de Clint Eastwood. Estados Unidos, DreamWorks, Warner Bros., Malpaso Productions, 2006. $141 \mathrm{~min}$. Cor. Som.

QUEIRÓS, Adirley. [Digital]. Branco sai, preto fica. Direção de Adirley de Queirós. Brasil, Cinco da Norte,
2014. 90 min. Cor. Som.

QUEIROZ, Simone. [Digital]. Era uma vez

Brasília. Produção de Adirley Queirós e Simone Queiroz. Direção de Adirley Queirós. Brasil, Cinco da Norte, Terratreme Filmes, 2017. 100 min. Cor. Som.

Notas

1 Doutor em Multimeios pela Universidade Estadual de Campinas (2007). Mestre em Multimeios pela Universidade Estadual de Campinas (2002). Pós-doutor pela Universidade de São Paulo (2013). Professor na Universidade Estadual de Campinas (UNICAMP - Instituto de Artes - Departamento de Cinema e Fotografia: Rua Elis Regina, Cidade Universitária. Cep: 13083854. Campinas/SP). Email: alsuppia@gmail.com.

2 Mestranda em Multimeios pela Universidade Estadual de Campinas (2016). Especialista em Roteiro de Ficção Audiovisual pelo Centro Universitário SENAC (2015). (UNICAMP - Instituto de Artes - Departamento de Cinema e Fotografia: Rua Elis Regina, Cidade Universitária. Cep: 13083854. Campinas/SP). Email: nat.romanzoti@gmail.com.

3 Tal polêmica serviu de combustível à geração da Nouvelle Vague francesa, especialmente no texto "Uma certa tendência do cinema francês" ("Une certaine tendence du cinéma français"), onde François Truffaut (2005) critica o cinema de roteiristas em seu país.

4 Ver TES (2013)

5 Cf. Documentário The man who fell to Earth: dreams of the hearth - entrevista com o escritor Paul Mayersberg, nos extras do DVD O homem que caiu na Terra, 
edição especial de luxo, produzido e distribuído por Vinyx Multimídia Ltda., São Paulo, 2017.

6 Ver, por exemplo, o roteiro de Iris Yamashita (2005) para o filme Cartas de Iwo Jima (Letters from Iwo Jima, Clint Eastwood, 2006), publicado pelo Warner Bros. Studios.

7 Assemblage é um termo francês trazido à arte por Jean Dubuffet em 1953, comumente utilizado para definir colagens com objetos e materiais tridimensionais.

8 Os dois formatos mais comuns para roteiros cinematográficos são os padrões conhecidos como "modelo europeu" (também chamado de "formato de áudio e vídeo" ou "formato rádio e TV"), e o "modelo americano" (também chamado de formato "master scenes"). No formato do tipo rádio e TV, a página do roteiro é dividida em duas colunas: uma referente à banda imagem, à esquerda (com descrições de ações), outra referente à banda sonora, à direita (com descrições de diálogo e/ou trilha sonora). No roteiro do tipo "americano" ou master scenes, também conhecido como "roteiro literário" (e cuja aparência é razoavelmente tributária do formato geral das peças de teatro), as páginas apresentam cabeçalho informando lugar (locação) e tempo, seguido de descrição de ação em texto corrido justificado, com diálogos centralizados e possíveis rubricas. A página não é dividida em colunas dispostas lado a lado.

9 Remake é um termo que vem do inglês e corresponde à refilmagem de produtos como filmes, telenovelas, jogos e seriados em novas produções audiovisuais.

208 PORTO ALEGRE | v. 22 | n. 38 | 2017 | p. 199-208 Sessões do Imaginário
10 Ver https://blcklst.com/.

11 No original em inglês: "We're asking what scripts people love. The market requires that they answer 'Which scripts do you think will result in a profitable movie?"'

(The Atlantic, 2017). 